\title{
A Scoping Review of Colorism in Schools: Academic, Social, and Emotional Experiences of Students of Color
}

\author{
Jandel Crutchfield ${ }^{1, *}$, Latocia Keyes ${ }^{2}$, Maya Williams ${ }^{3}$ and Danielle R. Eugene ${ }^{1}$ (I) \\ 1 School of Social Work, University of Texas at Arlington, Arlington, TX 76019, USA; danielle.eugene@uta.edu \\ Department of Social Work, Tarleton State University, Stephenville, TX 76402, USA; 1keyes@tarleton.edu \\ 3 School of Social Work, University of Washington, Seattle, WA 98105, USA; maya.angelica@utexas.edu \\ * Correspondence: jandel.crutchfield@uta.edu
}

Citation: Crutchfield, Jandel, Latocia Keyes, Maya Williams, and Danielle R. Eugene. 2022. A Scoping Review of Colorism in Schools: Academic,

Social, and Emotional Experiences of Students of Color. Social Sciences 11: 15. https://doi.org/10.3390/socsci 11010015

Academic Editor: Nigel Parton

Received: 20 October 2021

Accepted: 25 December 2021

Published: 5 January 2022

Publisher's Note: MDPI stays neutral with regard to jurisdictional claims in published maps and institutional affiliations.

Copyright: (C) 2022 by the authors. Licensee MDPI, Basel, Switzerland. This article is an open access article distributed under the terms and conditions of the Creative Commons Attribution (CC BY) license (https:// creativecommons.org/licenses/by/ $4.0 /)$.

\begin{abstract}
Students of color experience academic, social, and emotional challenges due to colorism in schools. The purpose of this scoping review is to compare the experiences with colorism of students from varying racial backgrounds (African Americans, Native Americans, Asians, and Latin) in U.S. public schools. It is predicted that the understudied group of Latinx and indigenous students of color will uniquely experience colorism in academic settings when compared to African American and Asian students. A 30 article literature review utilizing search dates from 1990 to 2020 was conducted employing a scoping review framework. Themes emerged that include: the privileging of lighter skin and more Eurocentric features in academic outcomes, the complicated social status created for students of color experiencing colorism in schools, and the increased potential for emotional challenges as a result of colorism. This review highlights possible school reform efforts to affirm all skin tones, reduce colorist biases, and offer mediation to mitigate colorist experiences in the school environment.
\end{abstract}

Keywords: colorism; skin color bias; implicit bias; students of color; public schools; academic outcomes; socioemotional outcomes

\section{Background}

Globally, racial justice movements have been sustained by youth (Ortega-Williams 2017). In the 21st century, children and youth of color have continued to push for justice in a racially divided world that often judges people based on appearance rather than merit. While racial categories vary widely across the world, there is a global linkage of these movements that seek to confront anti-blackness, or the rejection of people who appear to be Black (i.e., shape of nose, lips, texture of hair, color of eyes, skin color, etc.) (Plummer 2020). One study found anti-blackness, in the form of colorism, or preferential treatment of same-raced people based on their physical proximity to Whiteness (Blow 2021). Researchers defined Whiteness as European characteristics, which may include: light skin, a narrow nose, thin lips, and/or smooth hair (Russell et al. 1993).

Additionally, scholarship affirms that students with darker skin and Afrocentric phenotypes (e.g., wide nose and full lips) encounter many environmental barriers solely because of those characteristics (Hunter 2016). This worldwide phenomenon is demonstrated through protests against skin lighteners in India, which also occurs in African nations. Moreover, darker-skinned people in both Brazil and the United States experience economic, social, and educational limitations. Ultimately, colorism strikes a global chord of discrimination with particularly long lasting impacts for youth of color. This scoping review seeks to advance the knowledge on colorism for educational stakeholders, including the experiences of students of color in schools, who face daily instances of discrimination based on their skin tone and features. This study provides a historical view on colorism within the communities of color, including African Americans, Native Americans, Asians, and Latinx. The rationale for the study is followed by the methodology. The findings demonstrate the 
myriad of negative experiences of students of color with colorism in schools, followed by conclusions about the usefulness of the evidence found in this scoping review.

Colorism results in bias due to the privileging of light over dark skin and the preference for certain physical attributes that appear to be White (e.g., shape of the nose, texture of the hair, eye color) (Keith 2009; Maddox 2004; Banks 2015). To date, an overwhelming majority of colorism research has discussed the phenomenon among adult populations of color (Banks 2015; Devaraj et al. 2018; Monk 2015; Perreira and Telles 2014). For example, Reece (2019b), a notable colorism scholar, explores the economic advantages of lighter skin for African Americans both by examining their marriage patterns and the impact of obesity on income (i.e., obesity income penalty), stratified by race and skin color (Reece 2019c). Reece (2021) also found lighter skin African American people perpetuated their privilege by marrying lighter partners so that their children would be more affluent, with more access to education and social clubs in a Jim Crow south. Similarly, Reece (2021) suggests color dictates much of the social outcome of Americans, regardless of race.

In addition, youth conceptualize skin tone differences at early ages (Adams et al. 2016). Due to their analogous encounters with colorism and discrimination, African Americans, Native Americans, Asians, and Latinx are frequently grouped together in research on students of color (Lee and Bean 2007). It is acknowledged that colorism transcends racial groups, and much of the literature explores colorism through a racial lens. Thus, this introduction is used to describe the historical development of colorism within each racial group.

\subsection{African Americans}

Regarding African American children's conceptualization of colorism, the landmark "Doll Test" was seminal, as it evoked conversations around skin tone bias. Experimenters conducted the Doll Test by using White and Black dolls to analyze racial identification and preference among African American children (Clark and Clark 1939). Evidence from the "Doll Test" informed the authors that the intersection of prejudice, discrimination, and segregation lowered African American youths' self-esteem (Billante and Hadad 2010). In 2010, this study was recreated and tested on White and Black children within two age groups: 4-5 and 9-10 years old (Billante and Hadad 2010). Findings indicated African American youths' preference for dolls with lighter skin tones (James 2010). Overall, scholars found African American children may exhibit preferences for light or medium skin tones, and also begin negatively stereotyping dark skin tones, starting in kindergarten (Adams et al. 2016).

\subsection{Native Americans}

Historically, the interactions and norms among Native Americans were shaped by Euro-American settlers, especially in regard to colorism (Brown et al. 2018). In school settings from 1872-1910, skin tone hierarchies were implemented based on: ancestry, appearance, and level of assimilation (Halliburton 1977). As a result, Native children exhibited skin tone preferences towards their classmates. Specifically, in the Cherokee Nation, dark skin Native American students, or "full-blood", were ridiculed by light students of Caucasian and Native descent, or "mixed-blood" (Brown et al. 2018). Colorism has also created major divisions among the Native community in regard to their behaviors towards dark skin individuals (Hall 2010).

\subsection{Asian Populations}

Scholars found an aversion towards dark skin individuals in Asian history, as well (Thompson and McDonald 2015). The preference for light skin was paramount across Asian communities and predates their contact with Europeans (Rondilla and Spickard 2007). An abundance of cultural differences exists in Asia, yet the preference for light skin is universal (Isa and Kramer 2003; Russell et al. 1993). Even Asian youth had desired lighter or whiter skin tones to obtain greater upward mobility (Li et al. 2008). Among 
Asian college students in the United States, they reported light skin as the most important physical attribute (Fegley et al. 2008).

\subsection{Latinx Populations}

In Latin America, skin color is a prominent factor (Telzer and Garcia 2009). Distinctions are made regarding skin tone, such as "Blanco" that refers to light skin Latinos and "Indio" or "Moreno" that refers to dark skin Latinos (Uhlmann et al. 2002). Since the United States has a history of stigmatizing dark skin tones, scholars reported Latinos living in the U.S. had a tendency to associate positive qualities with light skin tones (Montalvo 2005; Stephens et al. 2012). As for Latinx youth, Latinos possessing dark skin tones experienced more negative self-perceptions and lower self-esteem when compared to Latinos possessing lighter skin tones (Telzer and Garcia 2009; Shelton et al. 2005). These experiences have resulted in skin color discrimination between Latinos (Santana 2018). However, this study comprehensively explores the consequences for students of color regarding colorism circumstances in every area of their life.

\subsection{Novelty and Scientific Contribution}

The assessment of where the field stands on providing evidence of how colorism impacts youth in public schools is a meaningful scientific contribution. The cross-racial analysis of literature is also substantial for the field that has largely explored issues of colorism within specific racial groups but not across racial groups.

\subsection{Rationale and Aims}

While the literature provides information about discipline and academic disproportionality based colorism within schools, the totality of these experiences has yet to be explored in a systematic way that promotes continuity within colorism and educational scholarship. Additionally, there are several reports on the experiences of African American students with colorism, but fewer with Latinx and other indigenous people of color to which this scoping review will contribute. The main objective of this study is to answer the research question "What are the academic, social, and emotional experiences and outcomes linked to colorism for students of color in American public schools?".

\section{Methods}

The scoping review protocol outlines the planning and developmental stages that began in 2019 by the first and second authors (Keyes and Crutchfield 2021). This protocol is published after receiving rigorous feedback, which was incorporated in the study selection process. This protocol outlines in detail the step-by-step processes to be undertaken for this scoping review.

The Preferred Reporting Items for Systematic Reviews/Meta-Analysis Extension for Scoping Reviews (PRISMA-ScR) to examine the literature methodically was used (e.g., Tricco et al. 2018). Scoping reviews are well known in the medical health field (Arksey and O'Malley 2005; Levac et al. 2010) that is becoming increasingly popular in branches of social sciences. Scoping reviews are typically conducted to research a broad topic utilizing extensive questions to establish gaps in the literature. On the contrary, a priori assists when analyzing systematic reviews and fixed factors aimed at a more narrow precise question or questionnaire. Scoping reviews are helpful in aggregating research studies in various fields with emerging evidence, as they are appropriate to address questions beyond those associated with the experience or efficacy of an intervention or implementation (Peters et al. 2015). The five-phrase framework follows: (1) Identifying the research question; (2) Identifying relevant studies; (3) Study selection; (4) Charting the data; (5) Collating, summarizing, and reporting the results (Arksey and O'Malley 2005). This process was utilized to conduct this review. 


\section{Five Phase Framework}

The following is a detailed guide of how this study implemented the five phase framework from Arksey and O'Malley, as is the standard for conducting scientific scoping reviews.

Identifying the research question. As indicated in the objectives, a broad research question was applied concerning the totality of colorism experiences and outcomes that students of color in the U.S. may encounter.

Identifying relevant studies. A comprehensive search was conducted using ten EBSCOhost databases: (1) Academic Search Complete, (2) Education Abstracts (H.W. Wilson), (3) Educational Administration Abstracts, (4) ERIC, (5) Primary Search, (6) Psychology and Behavioral Sciences Collection, (7) PsycARTICLES, (8) PsycINFO, (9) Social Work Abstracts, and (10) Race Relations. This electronic search consisted of an open date with no limiters, exact duplicates were removed automatically, and it generated six sources. Additional databases were set with publication dates 2000-2020; African American Communities and American Indian History and Culture both generated no sources. Final databases: JSTOR generated (1997) sources, Social Services Abstracts (364), Google Scholar (4); all were set with the same publication date. Keywords listed in all the electronic searches were $<$ colorism or colorist or skin tone* discrimination or skin preference* or skin tone bias or skin tone stratification or skin color discrimination AND primary school* or k-12 school* or grade school* ${ }^{*}$. The last conducted search date was January 28, 2020.

Study selection. The article inclusion criteria for the study were as follows: the population sample was K-12 (ages 5-18) African Americans, Asians, Latinx group, and Native Americans. The literature included research conducted in the United States and peer-reviewed publications that included all research designs along with grey literature (magazines, newspapers, theses, and dissertations). However, magazines and newspapers did not populate in the searches. Studies were retained that had populations over the age of 18 that may have entered college and were explicitly stated (i.e., 18-23 year-old college students). Thus, we define students as those up to age 18 (which may include those in college). Articles were excluded if the population was four years or under (birth-age four) and above (age 19-100) unless explicitly stated as college students or adolescents including 18 year-olds. Articles were also excluded if they did not reference African Americans, Asians, Latinx groups, and Native Americans. Additionally, literature with countries/continents located in Canada, Mexico, Africa, Asia, Europe, Australia, South America, and Antarctica were excluded. Finally, if the research conducted was a book review or came from the following type of grey literature (blogs, bulletins, speeches, press releases, course materials, conference papers, book chapters, white papers, government documents, working papers, and/or research reports), it was excluded.

Charting the data. The data files, (2371) were imported into Covidence, a review management software tool utilized for the screening process. Covidence system automatically removed (37) duplicates during the imported phase indicating the final total of (2334) to screen. The screening process consisted of three phases, see Figure 1: Methods Flow Chart. The second and third authors screened titles, abstracts, and full-texts independently, while the first author resolved disputes by consensus subsequent to each phase. Two additional duplicates appeared that were not found through the initial process of importing data into Covidence, which left (2332) as an aggregate to screen. The title and abstract screening excluded (2228) sources, a remainder (104) potential studies were assessed through full-text screening. Subsequent to the screening, it excluded 64 sources and a remainder of 40 studies were included for the final phase of screening, where the back of the references list of those studies were assessed. The second and third authors completed that process, and an additional 18 studies were included, which added 58 studies to extract data from. 


\section{Preferred Reporting Items for Systematic Reviews and Meta-Analyses Extension for Scoping Reviews (PRISMA-ScR)}
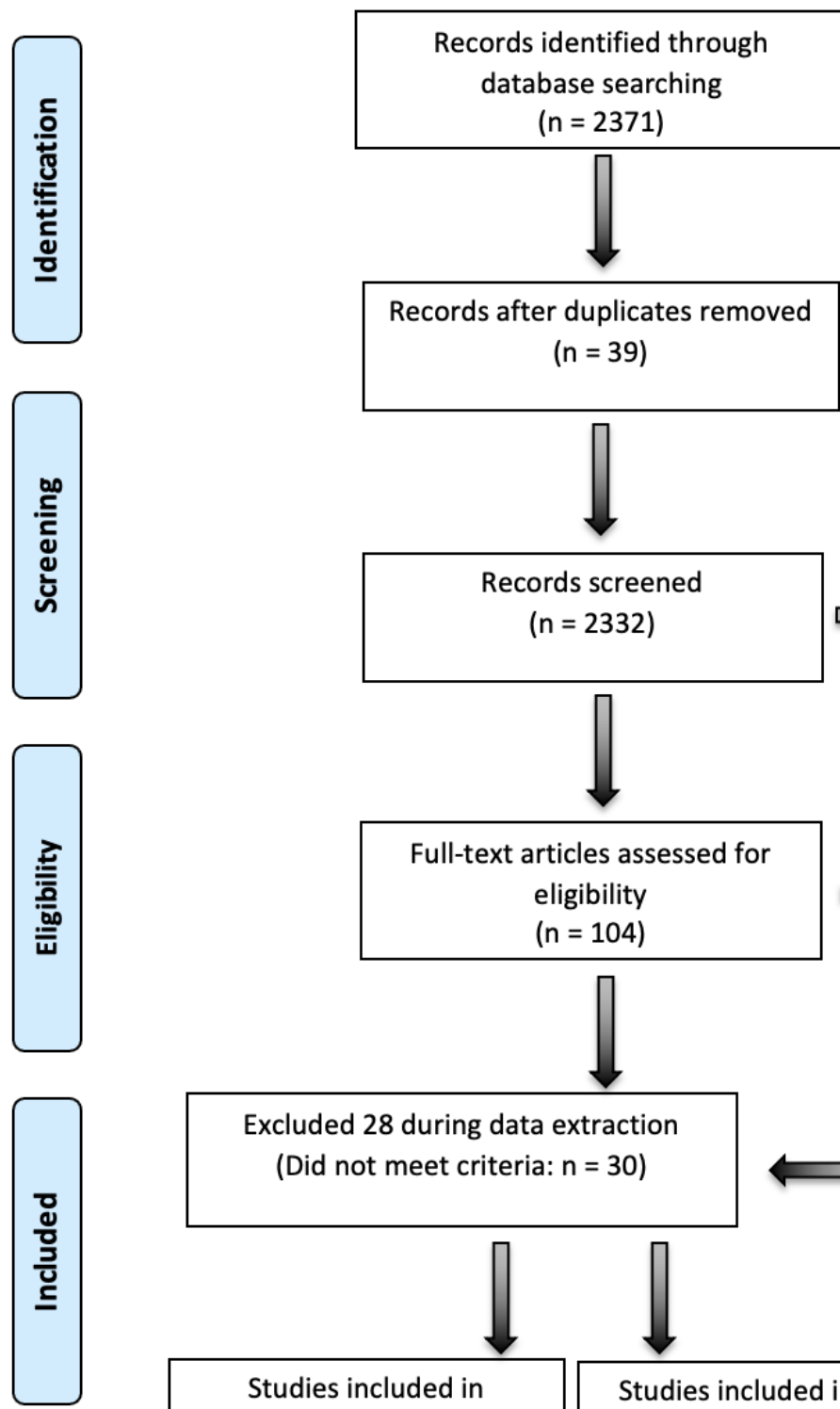

Records after duplicates removed $(n=39)$
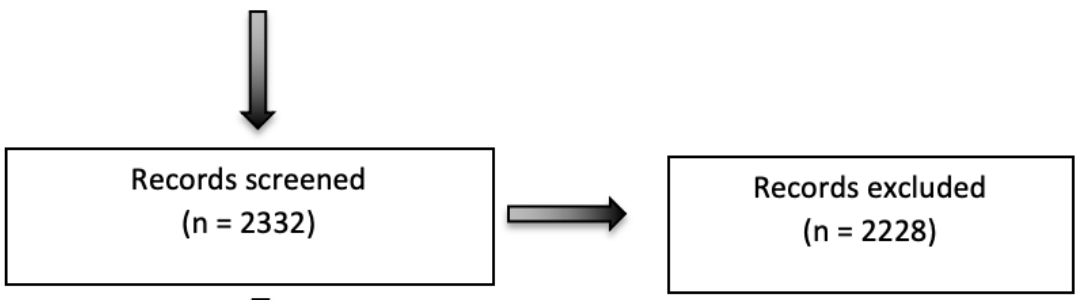

Excluded 28 during data extraction (Did not meet criteria: $\mathrm{n}=30$ )

Studies included $(n=40)$ Additional identified; reference list (18) $(n=58)$

Studies included in qualitative synthesis ( $n=10$ )

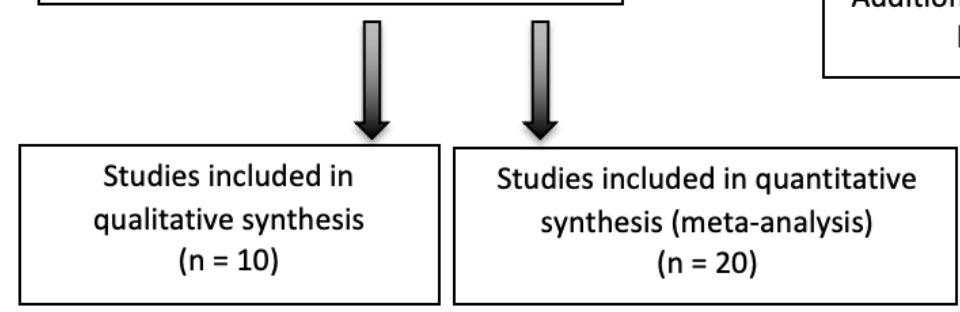

Full-text articles excluded, with reasons setting (4), adult population (10), did not meet criteria (50) ( $n=64)$

Total data sources included: $\underline{30}$

Figure 1. Methods flow chart. PRiSMA-ScR flow chart of scoping reviews (based on framework by Arksey and O’Malley (2005)).

The typical research study characteristics, publication date, study population/location, methodology, aim of the study, and results were extracted. During the data extraction, 28 studies were excluded not due to a fatal flaw, lack of evidence-based results, conclusion, or design issues, rather because they did not meet the overall inclusion criteria (Nippold 2011). This indicated that an aggregate of a final 30 studies were utilized as the data source.

Collating, summarizing, and reporting results. The data findings are arranged thematically according to the three prongs of the research question: academic, social, and emotional outcomes for students of color. Several of the individual articles fit into over- 
lapping categories and will only be summarized once. They will also be noted in the overlapping sections.

\section{Results}

Results are presented by type of outcome (academic, social, and emotional), as well as across racial groups. Individual articles are summarized for their main findings in each type of outcome. This presentation is then followed by a synthesis of the main concepts within each outcome. Finally, the discussion of the results describes major themes that manifest from the summary of the evidence.

\subsection{Results of Individual Sources of Evidence}

Individual sources of evidence are summarized here with details about the specific population under study and outcomes as related to the subtitle (academic, social, or emotional). Several of the results are cross-listed because they explore outcomes in each of these three areas.

\subsubsection{Academic Outcomes}

The academic outcomes explored the relationship between skin tone and educational achievement across racial groups. Branigan et al. (2013) assessed the relationship between skin color and educational attainment for native born non-Hispanic Black and White adults. They found a significant relationship between skin color and educational attainment for Black men and women. The findings indicated a range between zero and two additional years of education for lighter skin Black adults when compared to their darker skin counterparts.

Moreover, Fergus (2017) used qualitative interviews with six Mexican students from sixth through twelfth grade to assess the importance of skin color in how they identify themselves while attending a predominantly White school in a midwestern urban city. Mexican participants who possessed White features perceived themselves to be able to rise above any structural inequalities based on skin tone, while those who possessed Mexican presenting features (e.g., darker skin, eyes, and hair) believed they would experience challenges when overcoming institutional bias against Mexicans. Hunter's (2016) work aligns with the previous study by exhibiting educators' preference for lighter-skinned students rather than those with darker skin tones. This bias was evident through the favorable treatment and encouragement that light skin students received from teachers.

Kim and Calzada (2019) explored teacher impact on academic delay for Dominican American students. In the study, Dominican American boys whose phenotypic features appeared to be Black had lower academic achievement, which was mediated by lower teacher rated adaptive behavior in prekindergarten and kindergarten. Twenty-seven percent of the students in this group entered prekindergarten and kindergarten with academic delays. By the end of first grade, the percentage of the group that was academically delayed rose to $36 \%$. This is compared to Hispanic boys with whiter phenotypic features, who had a higher percentage $(30 \%)$ of academic delay before entering kindergarten. However, their delay decreased by $20 \%$ at the end of their first grade year, after they experienced high teacher rated adaptive behavior. This group of boys was uniquely impacted by teacher intervention, which was rooted in colorist biases.

In addition, Orozco and López (2015) used a sample of 90 students and collected survey responses to determine the association of skin color and perceived discrimination with grade point average. Through ordinary least squares regression, they found that with every 1 standard deviation increase in skin darkness, there was an associated 0.20 standard deviation decrease in grade point average. Ryabov (2016) used the ADD Health data to explore the educational attainment of Asian American and Hispanic American young adults in the U.S. as a function of skin tone, as well. He found a significant and strong positive association between skin tone and educational attainment. Meaning, participants' lighter skin tone was associated with a higher educational attainment and, therefore, grade 
point average (GPA). Ryabov (2013) used the same ADD Health data again to estimate the impact of skin tone on school-to-work and school-to-college transitions of African American youth. Through multinomial logistic regression, he found African American males with the lightest skin tones were more likely to find employment and to be enrolled in college than their same-race peers with darker skin tones. Additionally, the odds of finding a job were also significantly higher for African American females with the lightest skin tones. This is cross-listed as a social outcome.

Ryabov (2019) also used ADD Health data to explore Latinx adolescent educational outcomes. Those with whiter phenotypic features (e.g., light skin and blue eyes) had better academic outcomes than those with darker skin and brown eyes. Thompson and McDonald (2015) used ADD Health data to explore how perceived race and skin tone influenced grade point average, as well. They found significant variation across and within racial groups, with darker-skinned individuals receiving significantly lower grades than their lighter skin counterparts. This was also very noticeable in non-Black racial groups. Vasquez (2010) interviewed Latinx students about how their skin color influenced levels of support at school. Her findings suggest that protective support was given to lighter skin students, including mentorship, by school leaders when they were perceived to be White. However, when they discovered that the students were Mexican, this protective support was removed. Those who appeared to be more Mexican were consistently left without support. On the contrary, those who appeared more White could move in and out of the Mexican/White categorization, allowing them to receive additional support. This is cross-listed as a social outcome and an emotional outcome. In another study, Gullickson (2005) found that education and labor market outcomes were less influenced by skin color differences in 2005 than previously found. He used the National Survey of Black Americans Series (NSBA) wave one of adults aged 18 and older. This is cross-listed as a social outcome.

Monroe (2013) later wrote a conceptual piece for educators to consider the influence of colorism in their mentorship, professional experiences, school discipline, and when working with communities of color. Campbell (2009) found that multiracial youth had educational attainment more heavily linked to parental education and family income than skin color. Hannon et al. (2013) then conducted a logistic regression using the National Longitudinal Study of Youth (NLSY), which included a sample of 12-16 yearolds. The results indicated that darker-skinned Black girls were three times more likely to be suspended than lighter-skinned Black girls. Similar findings were discussed by Blake et al. (2017), using a multilevel logistic regression to control for background and school factors of an ADD Health sample of young African American female adolescents. The researchers found that colorism is a significant predictor of suspension and darkerskinned African American girls had the highest risk. On the other hand, Alarcón et al. (2000) discovered that skin color ratings were not significantly associated with grades, but that other characteristics, like the background of neighborhood, were associated with self-satisfaction among early childhood aged students.

Additionally, colorism can impact youth into adulthood through academic achievement and educational experiences. Biagas and Bianchi (2016) explored skin tone stratification among White and Hispanic undergraduates (with a sample that included 18 year-olds) at a large midwestern university. The authors viewed recordings of group interactions of three girls and three boys. The two groups included three individuals who were (1) White, (2) White-appearing Hispanic, and (3) Black-appearing Hispanic. In exploring who was the influencer of the group, Biagas and Bianchi (2016) found that both the White girl and boy were the major influencers of the group, followed by the White-appearing Hispanic, with the Black-appearing Hispanic having little influence on the group. This created in effect a three-tiered system of racial inequality. This is cross-listed as a social outcome. As for people aged 18 and over, Monk (2014) conducted over 6082 face-to-face interviews with persons of color aged 18 and over, which highlight the fact that skin tone stratification among African Americans still persists. The authors found that skin tone is significantly associated with Black Americans' educational attainment, household income, 
occupational status, and even the skin tone and educational attainment of their spouses. This is cross-listed as a social outcome.

\subsubsection{Social Outcomes}

The impacts of colorism on social well being have been explored across racial and ethnic groups. Bailey (2000) used a case study approach to investigate the classroom experience of one Dominican American student, analyzing how his phenotype led other students to mistakenly classify him as African American until he used the Spanish language. Even within his own Hispanic culture group he was not automatically accepted or associated as a member, until he spoke Spanish, due to his skin tone. For Hispanic students, phenotype and language factor into their social school experiences. Park (2011) observed preschool students in their social interactions with peers at school, as well. In her analysis, she found that these peer interactions were heavily based on skin tone and their understanding of skin tone was associated with Native heritage. This is also cross-listed as a social outcome.

In Bellinger's (2007) study, the author used participant observation and interviewed 15 African American teens aged 16-18 about their concepts of 'good hair'. The findings of this study indicate that many of the young African American girls changed their hair as a social status because 'good' was a concept taught by their mothers. In addition, they learned the myth of straightening hair as a source of manageability.

Bozo et al. (2018) found that Latina/o adolescents reported experiencing more microaggressions and having darker skin color than Asian American adolescents. The ANOVA analysis indicated, no main effect of gender was found for microaggressions, nor were there significant interactions between gender and ethnicity for microaggressions or skin color. Descriptive statistics showed participants reported having light brown facial skin color and experiencing microaggressions once per year or rarely. Facial skin color was positively associated with microaggressions $(r=0.12, p=0.033)$. Nativity status significantly moderated the association between skin color and microaggressions. Among foreign-born adolescents, there is a positive association between skin color and microaggressions $(\mathrm{B}=0.182$, $\mathrm{SE}=0.089, p=0.046)$. Among U.S.-born adolescents, there is no association between skin color and microaggressions $(\mathrm{B}=0.017, \mathrm{SE}=0.019, p=0.377)$.

Reece (2019a) used ADD Health data, which included over 90,000 adolescent responses across four waves of data collection beginning in 1994. In this study, Reece (2019a) found that skin color plays a role in shaping identity changes and lighter skin adolescents chose non-Black single race as their identity more often, while darker-skinned adolescents chose Black as their identity. However, the interviewer identified all of this subsample as Black. This study implies that there are social consequences when there is a mismatch between chosen identity of adolescents and perceived identity by others, such as the interviewer in this study.

Ryabov (2019) once again used ADD Health data to examine skin tone as a predictor of physical attractiveness and social status for Black men and women. The analysis shows that lighter-skinned young Black individuals attain a higher educational level, receive higher wages and enjoy better quality jobs than their darker-skinned coethnics. Moreover, the results show that more physically attractive young Black individuals, especially women, are advantaged in terms of educational attainment, wages, and job quality than their less physically attractive counterparts. These findings suggest that, among Black people, the skin color stratification coincides with that based on physical attractiveness to a large degree, with the implication being that the skin tone is a predictor of both physical attractiveness and social status for Black men and women. Eick (2010) used oral histories from Black and White high school students to determine how skin color limited access to social class post-Civil War. As poor Whites could dress up and be perceived as wealthy, poor Blacks could not do the same and were still seen as Black whether or not they had social class.

Park (2011), Ryabov (2019), Vasquez (2010), Gullickson (2005), Monk (2014, 2015), and Biagas and Bianchi (2016) are all cross-listed with academic outcomes and summarized there. 


\subsubsection{Emotional Outcomes}

Various emotional challenges have been identified for students experiencing colorism. Araujo and Borrell (2006) reviewed 14 articles about outcomes for Latinx in education and employment. Their review largely demonstrates the links between skin color discrimination and mental health outcomes. For example, Araujo and Borrell (2006) reported darkerskinned Mexicans who had a heightened experience with colorism also grappled with stress, leading to higher levels of depressive symptoms.

Ayers et al. (2013) examined a five-year randomized control trial of a substance abuse prevention intervention of 1150 Mexican students in eighth grade from 28 public schools in Phoenix, Arizona. Through their logistic regression, they demonstrated that ethnoracial appearance (i.e., phenotypic features like hair texture, eye/hair color, etc.) increases vulnerability to substance use and that this relationship is moderated by the strength of ethnic identity and generation status.

Calzada et al. (2019) investigated the association between skin color as a representation of racial phenotype and the mental health of young Latinx children. By the end of the first grade, children perceived as Black had higher ratings on internalizing and externalizing problems including anxiety, depression, and anger compared to those Latinx children perceived as White. This study found that darker-skinned Latinx kids are at increased risk for emotional health challenges. Monk (2015) reported on how skin tone was associated with perceived discrimination among African American young adults. The author revealed that skin tone was linked with issues of depression and even other health-related outcomes where Black/White health disparities exist. Additionally, Mathews and Johnson (2015) found that, for young African American college students, there were no significant associations between self-esteem and skin tone, nor social capital. Their results suggest a buffer of colorism for medium brown skin as opposed to very light or very dark-skinned African Americans.

Ramos et al. (2003) found that when Afro-Latina females were compared with European American, African American, and Latino adolescents, they reported statistically higher rates of depression due to their dual racial and ethnic identities. This is often impacted by their physical features like skin tone that lead others to identify them as Black.

Vasquez (2010) and Monk (2014) are cross-listed as academic and/or social outcomes and are summarized in those sections. Moreover, view the Appendix A: Table A1 Scoping Review Results.

\subsection{Synthesis of Results}

The majority of the studies identified in the scooping review illustrate experiences with colorism that influence academic outcomes for students of color. Whether through teacher bias towards those with darker skin and Afrocentric features or through the lack of perceived academic support in schools, the academic experiences of students of color are impacted by bias. This implicit and explicit bias against darker skin results in the privileging of lighter skin and more Eurocentric features. There were more articles on Latinx student populations than there were other student groups of color (e.g., African American, Native American, and Asian American). One of the most significant findings across all racial groups is that lighter skin and features are significantly associated with better academic achievement, including additional years of schooling.

Results of this scoping review also indicate the complicated social status and relationships for students of color facing colorism in schools. Namely, a focus on appearance dominated the articles ultimately included in the review, revealing that students might even change their hair and/or speech to avoid the consequences of colorism. Further, the experiences of students of color appear to be less warm and supportive among peers and teachers when they have more Afrocentric features. Even when students identified themselves as non-Black, others often identified them as Black due to their skin color and other phenotypic features, setting up conflict in their peer relationships. In essence, the studies found a three-tiered hierarchy in peer relationships in schools, where White students 
maintain a higher social status than lighter-skinned students of color, but lighter-skinned students of color maintain a higher social status than darker-skinned students of color on interracial campuses. Additionally, the fluidity of movement between social classes and privilege within schools for White or lighter-skinned students of color was apparent in the study findings when compared to darker-skinned students of color.

The results of the emotional outcomes analysis largely identified darker skin as a heavy risk factor for substance abuse and emotional problems, including externalizing and internalizing symptoms such as anger, anxiety, and depression when compared to lighterskinned Latinx students or those Latinx students perceived as White. These outcomes were seen in children as young as six years-old and also included an increased risk of substance abuse, in addition to other emotional problems.

\section{Discussion}

Colorism is a form of oppression that is expressed through a hierarchical treatment of individuals where, typically, favoritism or superiority are associated with those of lighter complexions, and those of darker complexions experience rejection and mistreatment in areas such as the educational system (Jackson-Lowman 2013). The objective of this scoping review was to assess the academic, social, and emotional experiences and outcomes linked to colorism for students of color in American public schools. The value of a scoping review that synthesizes the experiences of students with various racial/ethnic/skin tone is useful not only to researchers exploring the total impact of colorism but also to educators across schools with varying demographics. Rather than assuming that colorism only impacts certain groups, it is clear from this review that colorism is a shared experience across many cultural groups. Therefore, professional development for teacher and school staff (including leaders, counselors, social workers, and school resource officers) should address this important topic that impacts student outcomes. These staff have a large influence on the student experience and must be aware of the pervasiveness of colorism in schools.

While there are limitations to the study, several themes arose from this review. The first theme was confirmed in previous literature across ethnic and racial groups and was also included in the review: lighter skin tones and more Eurocentric features were linked to better academic outcomes, including higher GPAs, additional years of schooling, improved academic performance, more teacher/peer support, decreased rates of suspensions, and better school to work/college transitions. Thompson and McDonald (2015) suggest this occurs because of mediating factors such as teacher bias and exclusionary rules. In general, social inequalities stemming from colorism are produced through relationships such as teacher-student relationships within schools' punitive sanctions. As such, darker-skinned students face the greatest barriers to optimal educational outcomes due to differential treatment. This finding underscores the need for implicit bias and multicultural competence training that exposes teachers to the causes and consequences of stereotypes and cognitive biases (Quiocho and Rios 2000; Thompson and McDonald 2015). This supports the need for alternative disciplinary strategies that preclude students from missing key instructional time (Thompson and McDonald 2015).

The second theme was that students of color may engage in any number of behaviors to mitigate the experiences of colorism they face in schools. The review indicated how some students of color change their physical features (e.g., hair, speech) to simulate Eurocentric traits and characteristics. For students of color, and in particular darker-skinned female students, this was done to avoid colorist experiences and discrimination. Hunter (2016) revealed that empirical evidence suggests that skin color modifies outcomes and produces advantages in education for lighter-skinned students of color. In this way, lighter skin color and more Eurocentric features grant privilege and social capital in education, which often cannot be accessed or created by darker-skinned more Afrocentric-appearing students across racial groups. School staff and administrators who better understand colorism can advocate for the development of critical consciousness among students of color, for them to resist harmful phenotype-associated ideologies and messages. This allows for a 
psychological safe space in which students of color, in particular darker-skinned students, can form and sustain positive racial and academic identities (McGee et al. 2016). Furthermore, school staff can be intentional in their inclusion and promotion of belongingness for all the range of skin tones, with a focus on equitable treatment for darker-skinned more Afrocentric-appearing students across all racial groups.

The third theme was mental health and substance abuse outcomes which varied by skin tone. The review found that darker skin students of color experienced a higher likelihood of mental health and substance abuse problems when compared to lighterskinned students of color within the same racial group and then when compared to their White counterparts. This is an area that warrants more attention in future research because this finding may suggest that skin color impacts self-concept and self-esteem, which in turn influences overall mental health (Calzada et al. 2019). An example of this claim was observed by Perry et al. (2013), where the researchers found that in African American females, increased suicidal ideations and behaviors were associated with the identification of medium or darker skin tones. In addition, ethnic affirmation (i.e., positive feelings about one's race) was found to be a key protective factor. The literature reviewed for this study continues to show the shortcomings of the available research that provides depth of knowledge about the student experiences of multiple racial groups with colorism in schools. The result of the review is that multiple studies show how colorism in schools inhibits academic, social, and emotional outcomes for students of color.

A higher concentration of the literature focused on academic outcomes and colorist experiences among the African American and Latinx populations. Although colorism has been observed in Asian and Native American populations, the literature search yielded limited studies focusing directly on these populations during the last two decades. Beyond this, the majority of the studies were quantitative research using secondary datasets such as ADD Health, NLSY, and NSBA. The current study's findings confirm the outcomes in the current literature and help to fill some knowledge gaps to better understand colorism in schools for students of color.

\section{Limitations}

Despite strong findings that support the understanding of the experiences of students of color with colorism in schools, this study also had notable limitations. First, this study did not employ the framework that some scoping reviews use, a sixth phase, where consultation which is optional (Arksey and O'Malley 2005). Stakeholders were also not consulted, and as displayed in the protocol, this was consistent with others' scoping review process (e.g., Perreira et al. 2018; Lehning et al. 2017). The lived experiences informed by such people as public school students and educators could have possibly added more insight to the review. It is suspected that one of the keywords, discrimination, listed in the search generated much of the literature regarding racial discrimination, which did not meet the study criteria prior to the full-text screening method. For this review study, Covidence specifically generated reasons for excluding data sources during the entire screening procedure based on incorrect setting, publication date, and incorrect population age. The back of reference list limitation was consistent with the latter reasons. This study had 28 sources that did not meet all-inclusive criteria. These exclusion criteria were indicative of the incorrect type of study topics on racial discrimination. In contrast, this review illuminates an exhaustive scope of data collection and methodological rigor aligned with the guidelines of conducting a scoping review (Arksey and O'Malley 2005). Finally, although Asians and Native Americans experience colorism, the data revealed there is a dearth of literature in the child and adolescent category. More of the data collection in this study generated research on African Americans and the Latinx group.

\section{Conclusion and Future Directions}

The objective of this scoping review was to assess the academic, social, and emotional experiences and outcomes linked to colorism for students of color in American public 
schools. The current study's findings revealed three themes: (1) Across ethnic racial groups, lighter skin tones and more Eurocentric features were linked with better academic outcomes; (2) Students of color, in particular darker skin students, may alter physical features and characteristics to mitigate the consequences of colorism and discrimination in schools; (3) Darker skin students across racial groups had more experiences related to mental health and substance abuse problems. The evidence to date leaves advocates in this area with some optimism. Future directions for school reform leaders can focus on a commitment to culturally relevant pedagogy, curricula, and programming. Since "whiteness" is affirmed by default throughout U.S. society, educators and administrators must not be afraid to proactively affirm other skin tones that more resemble "blackness." In addition, other future directions should center on the constant monitoring of school and classroom discipline by checking for implicit or explicit colorist bias in patterns of both punishment, rewards, and achievement. Beyond this, providing targeted counseling and mediation to address and prevent colorist experiences for students of color is warranted. There is still much work to be done on reducing experiences with colorism in schools. On the contrary, all stakeholders in the success of students of color can take what has been found in this study as an impetus to engage in work that reduces colorist behaviors in public schools, which greatly affect darker skin students of color across racial groups.

Author Contributions: Conceptualization, J.C., methodology, J.C., L.K, and M.W., software, L.K., validation, J.C. and M.W., formal analysis, J.C., L.K, and M.W., writing-original draft preparation, J.C., L.K., M.W., and D.R.E., writing-reviewing and editing, J.C., D.R.E., L.K., and M.W. All authors have read and agreed to the published version of the manuscript.

Funding: This research received no external funding.

Data Availability Statement: The articles listed within this scoping review are available in online databases through most university library systems.

Conflicts of Interest: The authors declare no conflict of interest. 


\section{Appendix A}

Table A1. Scoping review results.

\begin{tabular}{|c|c|c|c|c|}
\hline Author(s)/Year & Study Population/Location & Methods & Aims of the Study & Results \\
\hline Alarcón et al. (2000) & $\begin{array}{c}\text { Puerto Rican children, mean age } 9.6 \\
\text { years old/Boston }\end{array}$ & $\begin{array}{l}\text { 3-year longitudinal, quantitative } \\
\text { survey study }\end{array}$ & $\begin{array}{l}\text { To examine the psychosocial } \\
\text { development, physical health, and } \\
\text { behavioral adjustment of Puerto Rican } \\
\text { children }\end{array}$ & $\begin{array}{l}\text { Children's ratings of their skin color were not associated with their } \\
\text { sex, school grade, ethnic identity, the child's or the parent's nativity, or } \\
\text { the racial or ethnic compositions of } 3 \text { social contexts: their } \\
\text { neighborhood, their classmates, and their closest friends. Puerto Rican } \\
\text { children did not show a preference for light-colored skin. Moreover, } \\
\text { there were no significant differences in self-esteem based on the } \\
\text { child's self-reported skin color. The lack of association between } \\
\text { self-esteem and skin color was interpreted in light of a developmental } \\
\text { tendency prevalent in early to middle childhood to place a positive } \\
\text { value on different aspects of one's self. }\end{array}$ \\
\hline Ayers et al. (2013) & $\begin{array}{l}\text { Data come from the sixth wave of a } \\
\text { 5-year randomized controlled trial of } \\
\text { a substance-use prevention } \\
\text { intervention that surveyed } 1150 \\
\text { Mexican heritage students, then in } \\
\text { eighth grade, from } 28 \text { public schools } \\
\text { in Phoenix, Arizona }\end{array}$ & Regression model & $\begin{array}{l}\text { To examine how Mexican students' } \\
\text { ethnoracial appearance predicted } \\
\text { adolescent substance use, and whether } \\
\text { the relationship differed by generation } \\
\text { status and strength of ethnic identity }\end{array}$ & $\begin{array}{l}\text { Results of the logistic regression reveal that generation status and } \\
\text { ethnic identity moderate the relationship between ethnoracial } \\
\text { appearance and substance use after adjustment for demographic } \\
\text { covariates. For use of alcohol, ethnoracial appearance does not have a } \\
\text { significant main effect; only the interaction between } \\
\text { second-generation status and ethnoracial appearance is significant. } \\
\text { For second-generation adolescents, increases in a more indigenous } \\
\text { ethnoracial appearance decrease the predicted odds of using alcohol. }\end{array}$ \\
\hline Bailey (2000) & $\begin{array}{l}\text { 11th grade student at Central High } \\
\text { School, a Providence City school of } \\
1350 \text { students, which is over } 20 \% \\
\text { Dominican }\end{array}$ & $\begin{array}{c}\text { Case study; ethnography } \\
\text { observation, interviewing, and } \\
\text { video-recording }\end{array}$ & $\begin{array}{l}\text { To describe on one } 17 \text { year-old } \\
\text { Dominican American's negotiation of } \\
\text { ethnic/racial identities during a single } \\
\text { class period at school }\end{array}$ & $\begin{array}{l}\text { Analysis of Wilson's talk and interaction reveals much about the local } \\
\text { roles of language and phenotype in the negotiation of identity, } \\
\text { showing that language can situationally precede phenotype as a } \\
\text { criterion for racial classification and that racial identities can shift } \\
\text { across linguistically, interactionally constructed contexts. }\end{array}$ \\
\hline Bellinger (2007) & $\begin{array}{l}15 \text { African American teens aged } \\
\text { 16-18 }\end{array}$ & $\begin{array}{l}\text { Participant observation and } \\
\text { open-ended interviews }\end{array}$ & $\begin{array}{l}\text { To explore the definition of "good hair" } \\
\text { and to understand the reasons young } \\
\text { African American women choose to } \\
\text { change physical attributes }\end{array}$ & $\begin{array}{l}\text { Respondents agree that "good hair" for Black men and women is an } \\
\text { unattainable myth perpetuated by generations of (mostly) Black } \\
\text { women. Younger African American women in the study change their } \\
\text { hair because their mothers did it with the hopes of giving one better } \\
\text { opportunities for new jobs or promotions. However, the downside to } \\
\text { changing their hair is that, to others, it appears they have lost their } \\
\text { racial pride. }\end{array}$ \\
\hline $\begin{array}{l}\text { Biagas and Bianchi } \\
\text { (2016) }\end{array}$ & $\begin{array}{l}\text { Whites and Latino/as with varying } \\
\text { skin tones; Midwestern University }\end{array}$ & $\begin{array}{c}\text { Experimental methods analyzed } \\
\text { through ANOVA }\end{array}$ & $\begin{array}{l}\text { To examine whether Whites exhibit } \\
\text { social status, in a manner consistent with } \\
\text { this three-tier system (Whites, Honorary } \\
\text { Whites, and Collective Blacks) }\end{array}$ & $\begin{array}{l}\text { White was influenced the most by White confederates; Whites were } \\
\text { influenced less by their light-skinned Latino/a confederates, and even } \\
\text { less by dark-skinned Latino/a confederates. This finding supports the } \\
\text { notion that skin tone and ethnic background have the equivalent } \\
\text { capacity to invoke processes to create the tripartite system of } \\
\text { racial/ethnic inequality. }\end{array}$ \\
\hline
\end{tabular}


Table A1. Cont.

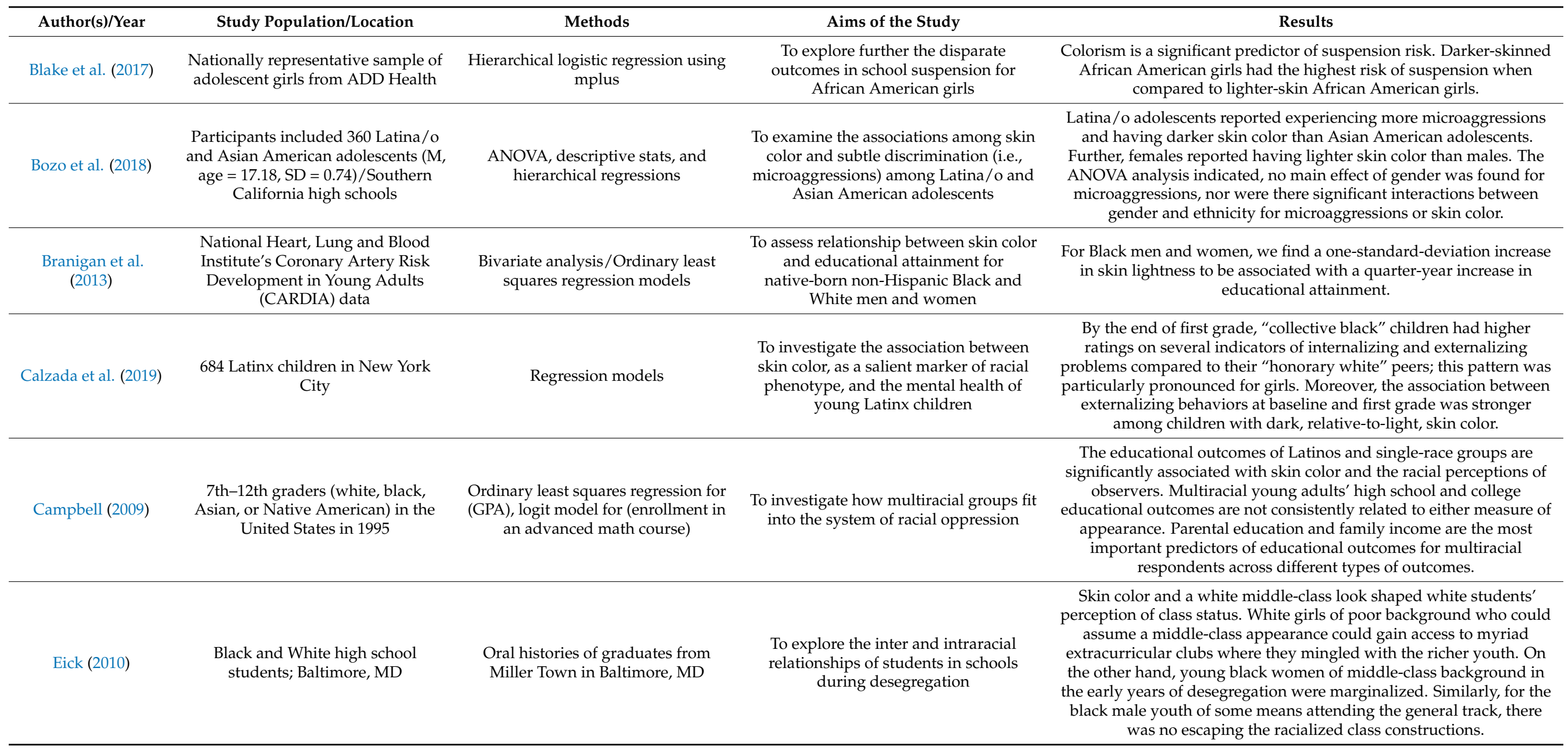


Table A1. Cont.

\begin{tabular}{|c|c|c|c|c|}
\hline Author(s)/Year & Study Population/Location & Methods & Aims of the Study & Results \\
\hline Fergus (2017) & $\begin{array}{l}\text { Six 9th-12th grade students; Central } \\
\text { American and Mexican } \\
\text { student/Midwestern city }\end{array}$ & Phenomenological framework & $\begin{array}{l}\text { This explores how six Mexican students } \\
\text { signal the meaningfulness of skin color } \\
\text { in their identification as } \\
\text { Latino/a/Mexican and how such } \\
\text { experiences interact with their notions of } \\
\text { the opportunity structure }\end{array}$ & $\begin{array}{l}\text { Six Mexican students who discussed teachers identifying them as } \\
\text { "White-looking" or "Hispanic/Mexican-looking". The } \\
\text { "White-looking" students perceived themselves as being able to } \\
\text { permeate structural barriers; meanwhile, the } \\
\text { "Hispanic/Mexican-looking" students believed such barriers affected } \\
\text { their ability to "make it", regardless of their aspirations }\end{array}$ \\
\hline Gullickson (2005) & $\begin{array}{c}\text { Black Americans } / 18 \text { and up from } \\
\text { the National Survey of Black } \\
\text { Americans }\end{array}$ & Multivariate models & $\begin{array}{l}\text { To examine the changes across cohorts in } \\
\text { differentials within educational, } \\
\text { occupation, and spousal attainment }\end{array}$ & $\begin{array}{l}\text { The authors found significant declines in skin tone differentials for } \\
\text { younger cohorts, in terms of educational and labor market outcomes, } \\
\text { but not in terms of spousal attainment. These declines begin with } \\
\text { cohorts born in the mid-1940s. In addition, there is evidence of period } \\
\text { declines of skin tone differentials in occupational attainment in the } \\
\text { 1980s. I discuss possible explanations for the declines. }\end{array}$ \\
\hline Hannon et al. (2013) & $\begin{array}{c}\text { African American youth aged 12-16 } \\
\text { years old/National Longitudinal } \\
\text { Survey of Youth }\end{array}$ & Logistic regression & $\begin{array}{l}\text { To examine whether skin darkness } \\
\text { affects the likelihood that African } \\
\text { Americans will experience school } \\
\text { suspension }\end{array}$ & $\begin{array}{l}\text { This was disproportionately driven by the experiences of African } \\
\text { American females. The odds of suspension were about } 3 \text { times greater } \\
\text { for young African American women with the darkest skin tone } \\
\text { compared to those with the lightest skin tone. }\end{array}$ \\
\hline Hunter (2016) & $\begin{array}{l}\text { African American and Latina/o } \\
\text { children in schools }\end{array}$ & Literature review & $\begin{array}{l}\text { To emphasize and explore the many } \\
\text { ways that color-based discrimination } \\
\text { affects the educational trajectories of } \\
\text { Latina/o and African American children }\end{array}$ & $\begin{array}{l}\text { Her findings sum up the resolutions to combat colorism: Teachers and } \\
\text { administrators can start by bringing a critical lens to existing } \\
\text { discussions of racism in the curriculum. For example, school leaders } \\
\text { can initiate a discussion of colorism within the annual discussion of } \\
\text { Latina/o Heritage and Black History Months. Recruiting more } \\
\text { African American and Latina/o teachers and administrators, as well } \\
\text { as teachers and administrators of any race who are more familiar with } \\
\text { Black and Latina/o cultures and communities, is crucial in the } \\
\text { endeavor. A more diverse staff, however, is not enough. Ongoing staff } \\
\text { development around issues of race, color, and inclusion, with a focus } \\
\text { on self-reflection, is central to dismantling colorism. }\end{array}$ \\
\hline
\end{tabular}


Table A1. Cont.

Author(s)/Year Study Population/Location

750 Latino children, prekindergarten and kindergarten students/New York City
Longitudinal study using structural equation models (SEM)
To investigate the association between skin color and academic achievement in young Latino students
Methods

Aims of the Study

\section{Results}

The findings showed that for Dominican-origin (Dominican American =DA) boys, being "collectively black" was indirectly associated with lower academic achievement in first grade, mediated by lower teacher-rated adaptive behavior in prekindergarten or kindergarten. Specifically, when the "collective black" boys entered prekindergarten or kindergarten, $27 \%$ were academically delayed, and by the end of first grade, the percentage at academic risk had increased to $36 \%$. In contrast, when the "honorary white" boys entered school, $30 \%$ were delayed on academic school readiness, but only $21 \%$ were at risk by the end of first grade. Thus, given that only DA children were rated in the darkest skin color category, DA boys who are "collective black" emerged as the group at possible highest risk for academic underachievement. For DA girls, skin color was not significantly associated with academic achievement in first grade.

ANOVA results of skin tone and the self-esteem index indicate that the participant's skin tone did not have a significant effect on their

African American women (between the ages of 18 and 23)/Historically Black College/University at a Southern University

Mixed methods survey research and qualitative responses, ANOVA

To explore participants' perceptions and preferences for skin complexion

To explore how skin tone stratification among black Americans persists into the 21st century
African American sample is

Monk (2015) households in the 48 coterminous states with one adult age 18 and ove
Multistage probability design

To examine the relationship between skin tone, discrimination, and health among African Americans level of self-esteem, $\mathrm{F}(2,84)=1.196, p=0.307$. Women who measured high in self-esteem would also measure high in social capital, irrespective of skin complexion.

The authors found that skin tone is significantly associated with black

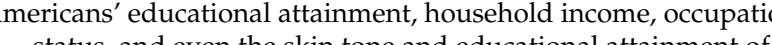
their spouses.

Skin tone is a significant predictor of multiple forms of perceived discrimination (including perceived skin color discrimination from whites and blacks) and, in turn, these forms of perceived

discrimination are significant predictors of key health outcomes, such as depression and self-rated mental and physical health. Intraracial health differences related to skin tone (and discrimination) often rival or even exceed disparities between blacks and whites as a whole. The author also finds that self-reported skin tone, conceptualized as a form of embodied social status, is a stronger predictor of perceived discrimination than interviewer-rated skin tone.
To explore how and why colorism otivates imbalances within
The author recommends that educators consider colorism during mentorship, professional experiences, school discipline, and in when working with additional communities of color. 
Table A1. Cont.

\begin{tabular}{|c|c|c|c|c|}
\hline Author(s)/Year & Study Population/Location & Methods & Aims of the Study & Results \\
\hline $\begin{array}{l}\text { Orozco and López } \\
\text { (2015) }\end{array}$ & $\begin{array}{l}\text { Mexican American high school } \\
\text { students/Southern Arizona }\end{array}$ & $\begin{array}{l}\text { Ordinary least squares regression } \\
\text { model }\end{array}$ & $\begin{array}{l}\text { To examine the extent to which } \\
\text { perceived discrimination, acculturation, } \\
\text { racial phenotype, familiarity with SB } \\
\text { 1070, and stress associated with SB } 1070 \\
\text { are related to acculturative stress }\end{array}$ & $\begin{array}{l}\text { Perceived discrimination and skin color are both negatively related to } \\
\text { grades, whereas maintaining Spanish is positively related to grades, } \\
\text { collectively accounting for almost } 20 \% \text { of the variability in grades. For } \\
\text { skin color, each } 1 S D \text { in skin darkness increase is associated with a } \\
\text { decrease of } 0.20 S D \text { in grades. There is a moderating effect of } \\
\text { discrimination on attachment, accounting for approximately } 13 \% \text { of } \\
\text { the variability in attachment scores. }\end{array}$ \\
\hline Park (2011) & $\begin{array}{l}\text { Six young children ages } 3.5 \text { to } 5.5 ; 3 \\
\text { European, } 3 \text { multicultural } \\
\text { groups/metropolitan area on the } \\
\text { West Coast }\end{array}$ & $\begin{array}{l}\text { Qualitative observations of regular } \\
\text { classroom activities and discussions }\end{array}$ & $\begin{array}{c}\text { To explore how children learn about } \\
\text { diversity }\end{array}$ & $\begin{array}{l}\text { First, students made claims to identities that demonstrated the } \\
\text { significance of physical markers commonly associated with race } \\
\text { including skin color. Students were stretched in new directions in } \\
\text { their social interactions with peers and had valuable opportunities to } \\
\text { use experiences beyond their own to gain new insights about racial } \\
\text { and ethnic diversity. }\end{array}$ \\
\hline Ramos et al. (2003) & $\begin{array}{l}\text { Add Health, a nationally } \\
\text { representative survey sample of over } \\
90,000 \text { adolescents across four waves } \\
\text { of data collection over } 20+\text { years }\end{array}$ & $\begin{array}{c}\text { Ordinary least squares regression } \\
\text { model }\end{array}$ & $\begin{array}{l}\text { To compare depressive symptoms } \\
\text { among European Americans vs. African } \\
\text { Americans, Latinos, and Afro-Latinos }\end{array}$ & $\begin{array}{l}\text { Afro-Latina females, who exhibit characteristics like skin tone that are } \\
\text { often associated as "Black", reported statistically higher rates of } \\
\text { depression than males of all of ethnic groups. This suggests that } \\
\text { Afro-Latina females face higher levels of stress due to their dual ethnic } \\
\text { and racial identities of African American and Latina. }\end{array}$ \\
\hline Reece (2019a) & $\begin{array}{l}\text { Add Health, a nationally } \\
\text { representative survey sample of over } \\
90,000 \text { adolescents across four waves } \\
\text { of data collection over } 20+\text { years }\end{array}$ & Multinomial logistic regression & $\begin{array}{l}\text { To examine the effect of skin tone on } \\
\text { racial identity change, exploration of } \\
\text { adolescent racial identity formation }\end{array}$ & $\begin{array}{l}\text { Results reveal that lighter-skinned adolescents are more likely to } \\
\text { change their identification to a non-black single race, while } \\
\text { darker-skinned adolescents are more likely to change their } \\
\text { identification to black only. Color seems to play a large role in shaping } \\
\text { identity changes. }\end{array}$ \\
\hline $\begin{array}{l}\text { Ryabov and Goza } \\
\qquad(2014)\end{array}$ & $\begin{array}{l}\text { National Longitudinal Study of } \\
\text { Adolescent Health (sample of } \\
\text { adolescents and young adults) }\end{array}$ & Multivariate analyses & $\begin{array}{l}\text { To examine the impact of phenotyping } \\
\text { on academic and employment outcomes } \\
\text { among Latino adolescents/young adults }\end{array}$ & $\begin{array}{l}\text { Results indicate that, among Latinos, light skin and blue eyes are } \\
\text { associated with better academic outcomes than having dark skin and } \\
\text { brown eyes, while those with darker skin enter the labor market } \\
\text { earlier than their light-skinned coethnics. }\end{array}$ \\
\hline Ryabov (2013) & $\begin{array}{l}\text { Add Health resulted in a nationally } \\
\text { representative sample of adolescents } \\
\text { between the ages of } 12 \text { and } 21 \text { years }\end{array}$ & Multinomial logistic modeling & $\begin{array}{l}\text { To estimate the impact of skin tone on } \\
\text { school-to-work and school-to-college } \\
\text { transitions of African American youths }\end{array}$ & $\begin{array}{l}\text { The findings suggest that African American males with the lightest } \\
\text { skin tone were more likely to find a job and to be in college than their } \\
\text { coracial peers with darker skin tones. The odds of finding a full-time } \\
\text { job were also significantly higher for African American females with } \\
\text { the lightest skin tone. Family background factors, marital status, prior } \\
\text { achievement, and average school socioeconomic status matter } \\
\text { the most. }\end{array}$ \\
\hline
\end{tabular}


Table A1. Cont.

\begin{tabular}{|c|c|c|c|c|}
\hline Author(s)/Year & Study Population/Location & Methods & Aims of the Study & Results \\
\hline Ryabov (2019) & $\begin{array}{l}\text { Add Health sample includes only } \\
\text { African American respondents }\end{array}$ & Structural equation modeling & $\begin{array}{l}\text { To test the hypothesized relationship } \\
\text { between skin tone, physical } \\
\text { attractiveness, gender, and status } \\
\text { attainment, while controlling for a range } \\
\text { of individual socio-economic and family } \\
\text { effects }\end{array}$ & $\begin{array}{l}\text { The analysis shows that lighter-skinned young Blacks attain a higher } \\
\text { educational level, receive higher wages and enjoy better-quality jobs } \\
\text { than their darker-skinned coethnics. Among blacks, the skin color } \\
\text { stratification coincides with physical attractiveness to a large degree, } \\
\text { with the implication being that the skin tone is a predictor of both } \\
\text { physical attractiveness and social status for black men and women. }\end{array}$ \\
\hline Ryabov (2016) & Add Health & Regression & $\begin{array}{l}\text { To evaluate the educational attainment } \\
\text { of Asian American and Hispanic young } \\
\text { adults in the United States as a function } \\
\text { of skin tone and other covariates }\end{array}$ & $\begin{array}{c}\text { Results consistently point to a strong association between educational } \\
\text { attainment and the lightness of skin tone. The findings also suggest } \\
\text { that the aforementioned relationship is the strongest among U.S. } \\
\text { young adults of Filipino and Puerto Rican descent. }\end{array}$ \\
\hline $\begin{array}{l}\text { Thompson and } \\
\text { McDonald (2015) }\end{array}$ & Add Health & Regression models & $\begin{array}{l}\text { To examine the extent to which } \\
\text { self-identified race category and } \\
\text { perceived skin tone influence } \\
\text { educational performance independently } \\
\text { and simultaneously }\end{array}$ & $\begin{array}{l}\text { Analyses show significant skin tone differences in grade point average } \\
\text { (GPA) both across and within racial groups, with darker skin-toned } \\
\text { individuals receiving significantly lower grades than their lighter } \\
\text { skin-toned counterparts. Net of controls and skin tone differences in } \\
\text { GPA are essentially flat among African Americans but are notably } \\
\text { stronger among other race/ethnic groups. These findings highlight } \\
\text { the interplay between racial categorization and colorism by revealing } \\
\text { the categorical disadvantage of racial stigma versus the more fluid } \\
\text { colorism boundaries of nonblack groups. }\end{array}$ \\
\hline Vasquez (2010) & $\begin{array}{l}\text { Twenty-nine third-generation } \\
\text { Mexican Americans ages } 17 \text { and } \\
\text { up/Northern and Southern } \\
\text { California }\end{array}$ & Qualitative & $\begin{array}{l}\text { To explore how the lives of middle-class } \\
\text { third-generation Mexican Americans } \\
\text { both racialized and gendered }\end{array}$ & $\begin{array}{l}\text { Findings show that Mexican women are afforded more "flexible } \\
\text { ethnicity" than Mexican men. Accordingly, Mexican men are more } \\
\text { rigorously racialized than Mexican women. They are racialized } \\
\text { through exoticization, whereas Mexican men are racialized as threats } \\
\text { to safety. Lighter-skinned Mexican individuals escaped } \\
\text { consistent racialization. }\end{array}$ \\
\hline
\end{tabular}




\section{References}

Adams, Elizabeth, Beth Kurtz-Costes, and Adam Hoffman. 2016. Skin tone bias among African Americans: Antecedents and consequences across the life span. Developmental Review 40: 93-116. [CrossRef]

Alarcón, Odette, Laura Szalacha, Sumru Erkut, Jacqueline Fields, and Cynthia Garcia Coll. 2000. The Color of My Skin: A measure to assess children's perceptions of their skin color. Applied Developmental Science 4: 208-21. [CrossRef]

Araujo, Beverly, and Luisa Borrell. 2006. Understanding the link between discrimination, life chances, and mental health outcomes among Latinos. Hispanic Journal of Behavioral Sciences 28: 245-66. [CrossRef]

Arksey, Hilary, and Lisa O'Malley. 2005. Scoping studies: Towards a methodological framework. International Journal of Social Research Methodology 8: 19-32. [CrossRef]

Ayers, Stephanie, Stephen Kulis, and Flavio Marsiglia. 2013. The impact of ethnoracial appearance on substance use in Mexican heritage adolescents in the southwest United States. Hispanic Journal of Behavioral Sciences 35: 227-40. [CrossRef] [PubMed]

Bailey, Benjamin. 2000. Language and negotiation of ethnic/racial identity among Dominican Americans. Language in Society 29: 555-82. [CrossRef]

Banks, Taunya Lovell. 2015. Colorism among South Asians: Title VII and skin tone discrimination. Washington University Global Studies Law Review 14: 665.

Bellinger, Whitney. 2007. Why African American Women Try to Obtain 'Good Hair'. Available online: http:/ / citeseerx.ist.psu.edu/ viewdoc/download?doi=10.1.1.473.1938\&rep=rep1\&type=pdf (accessed on 20 October 2021).

Biagas, David, and Alison Bianchi. 2016. The Latin Americanization Thesis: An Expectation States Approach. Social Forces 94: 1335-58.

Billante, Jill, and Chuck Hadad. 2010. Study: White and Black Children Biased toward Lighter Skin. CNN. Available online: http:/ /www.cnn.com/2010/US/05/13/doll.study/index.html (accessed on 20 October 2021).

Blake, Jamilia, Verna Keith, Wen Luo, Huong Le, and Phia Salter. 2017. The role of colorism in (explaining African American females' suspension risk. School Psychology Quarterly: The Official Journal of the Division of School Psychology, American Psychological Association 32: 118-30. [CrossRef] [PubMed]

Blow, Charles. 2021. The Impact of the Browning of America on Anti-Blackness. New York Times, November 14. Available online: https:/ / www.nytimes.com/2021/11/14/opinion/latinos-colorism-anti-blackness.html (accessed on 20 October 2021).

Bozo, Jesse, Michelle Revels-Macalinao, and Virginia Huynh. 2018. Examining skin color and discrimination among ethnic minority adolescents. Race and Social Problems 10: 320-31. [CrossRef]

Branigan, Amelia, Jeremy Freese, Assat Patir, Thomas McDade, Kiang Liu, and Catarina Kiefe. 2013. Skin color, sex, and educational attainment in the post-civil rights era. Social Science Research 42: 1659-74. [CrossRef]

Brown, Donna, Karen Branden, and Ronald Hall. 2018. Native American Colorism: From Historical Manifestations to the Current Era. American Behavioral Scientist 62: 2023-36. [CrossRef]

Calzada, Esther, Yeon Woo Kim, and Jaimie O'Gara. 2019. Skin color as a predictor of mental health in young latinx children. Social Science \& Medicine 238: 112467. [CrossRef]

Campbell, Mary E. 2009. Multiracial Groups and Educational Inequality: A Rainbow or a Divide? Social Problems 56: $425-446$. [CrossRef]

Clark, Kenneth, and Mamie Clark. 1939. The development of consciousness of self and the emergence of racial identification in Negro preschool children. The Journal of Social Psychology 10: 591-99. [CrossRef]

Keyes, Latocia, and Jandel Crutchfield. 2021. Beyond the crayon box: A scoping review protocol for colorism in schools. Social Science Protocols 3: 1-8.

Devaraj, Srikant, Narda Quigley, and Pankaj Patel. 2018. The effects of skin tone, height, and gender on earnings. PLoS ONE 13: e0190640. [CrossRef] [PubMed]

Eick, Caroline. 2010. Student relationships across social markers of difference in a Baltimore County, Maryland, comprehensive high school, 1950-1969. History of Education Quarterly 50: 359-89. [CrossRef]

Fegley, Suzanne, Margart Spence, Tyhesa Goss, VinjayHarpalani, and Nicole Charles. 2008. Colorism embodied: Skin tone and psychological well-being in adolescence. In Body in Mind, Mind in Body: Developmental Perspectives on Embodiment and Consciousness. Edited by Willis Overton and Ulrich Muller. Mahwah: Erlbaum, pp. 281-312.

Fergus, Edward. 2017. Because I'm light skin ... they think I'm italian: Mexican students' experiences of racialization in predominantly white schools. Urban Education 52: 460-90. [CrossRef]

Gullickson, Aaron. 2005. The significance of color declines: A re-analysis of skin tone differentials in post-civil rights America. Social Forces 84: 157-180. [CrossRef]

Hall, Ronald. 2010. Native Americans: Manifestations of White Influences. In An Historical Analysis of Skin Color Discrimination in America. New York: Springer, pp. 91-107.

Halliburton, R. 1977. Red Over Black: Black Slavery among the Cherokee Indians. Westport: Greenwood Press.

Hannon, Lance, Robert DeFina, and Sarah Burch. 2013. The relationship between skin tone and school suspension for African Americans. Race and Social Problems 5: 281-95. [CrossRef]

Hunter, Margaret. 2016. Colorism in the classroom: How skin tone stratifies African American and Latina/o students. Theory into Practice 55: 54-61. [CrossRef]

Isa, Masako, and Eric Mark Kramer. 2003. Adopting the Caucasian 'Look': Reorganizing the Minority Face. In The Emerging Monoculture: Assimilation and the "Model Minority". Edited by Kramer Eric Mark. Westport: Praeger, pp. 41-74. 
Jackson-Lowman, Huberta. 2013. An analysis of the impact of Eurocentric concepts of beauty on the lives of African American women. In African American Women: Living at the Crossroads of Race, Gender, Class, and Culture. Edited by Jackson-Lowman Huberta. San Diego: Cognella Academic Publishing, pp. 155-72.

James, Rawn, Jr. 2010. Root and Branch: Charles Hamilton Houston, Thurgood Marshall, and the Struggle to End Segregation. London: Bloomsbury Publishing.

Keith, Verna. 2009. A colorstruck world: Skin tone, achievement, and self-esteem among African American women. In Shades of Difference: Why Skin Color Matters. Stanford: Stanford University Press, pp. 25-39.

Kim, Yeon Woo, and Esther Calzada. 2019. Skin color and academic achievement in young, Latino children: Impacts across gender and ethnic group. Cultural Diversity E Ethnic Minority Psychology 25: 220-31. [CrossRef]

Lee, Jennifer, and Frank Bean. 2007. Reinventing the color line immigration and America's new racial/ethnic divide. Social Forces 86: 561-86. [CrossRef]

Lehning, Amanda, Emily Joy Nicklett, Joan Davitt, and Hilary Wiseman. 2017. Social work and aging in place: A scoping review of the literature. Social Work Research 41: 235-48. [CrossRef]

Levac, Danielle, Heather Colquhoun, and Kelly O'Brien. 2010. Scoping studies: Advancing the methodology. Implementation Science 5: 69. [CrossRef] [PubMed]

Li, Eric, Hyun Jeong Min, and Russell Belk. 2008. Skin lightening and beauty in four Asian cultures. Advances in Customer Research 35: 444-49.

Maddox, Keith. 2004. Perspectives on racial phenotypicality bias. Personality and Social Psychology Review 8: 383-401. [CrossRef]

Mathews, Tayler, and Glenn Johnson. 2015. Skin Complexion in the Twenty-First Century: The Impact of Colorism on African American Women. Race, Gender \& Class 22: 248-74.

McGee, Ebony, Adam Alvarez, and H. Richard Milner IV. 2016. Colorism as a salient space for understanding in teacher preparation. Theory Into Practice 55: 69-79. [CrossRef]

Monk, Ellis. 2014. Skin Tone Stratification among Black Americans, 2001-2003. Social Forces 92: 1313-37. [CrossRef]

Monk, Ellis, Jr. 2015. The cost of color: Skin color, discrimination, and health among African-Americans. American Journal of Sociology 121: 396-444. [CrossRef]

Monroe, Carl. 2013. Colorizing educational research: African American life and schooling as an exemplar. Educational Researcher 42: 9-19. [CrossRef]

Montalvo, Frank. 2005. Surviving race: Skin color and the socialization and acculturation of Latinas. Journal of Ethnic and Cultural Diversity in Social Work 13: 25-43. [CrossRef]

Nippold, Marilyn. 2011. The fatal flaw: What it is and how to avoid it. Language, Speech, and Hearing Services in Schools 42: 1-2. [CrossRef]

Orozco, Richard, and Francesca López. 2015. Impacts of Arizona's sb 1070 on Mexican American students' stress, school attachment, and grades. Education Policy Analysis Archives 23: 42. [CrossRef]

Ortega-Williams, Anna. 2017. Is Organizing a Pathway for Wellbeing and Post-Traumatic Growth for Black Youth in New York City? Exploring Recovery from Historical Trauma and Systemic Violence. ETD Collection for Fordham University. AAI10279034. New York: Fordham University. Available online: https:/ / research.library.fordham.edu/dissertations/AAI10279034 (accessed on 20 October 2021).

Park, Caryn. 2011. Young children making sense of racial and ethnic differences: A sociocultural approach. American Educational Research Journal 48: 387-420. [CrossRef]

Perreira, Krista, and Edward Telles. 2014. The color of health: Skin color, ethnoracial classification, and discrimination in the health of Latin Americans. Social Science \& Medicine 116: 241-50. [CrossRef]

Perreira, Tyrone, Laure Perrier, and Melissa Prokopy. 2018. Hospital Physician Engagement. Medical Care 56: 969-75. [CrossRef]

Perry, Brea, Danielle Stevens-Watkins, and Carrie Oser. 2013. The moderating effects of skin color and ethnic identity affirmation on suicide risk among low-SES African American women. Race Social Problems 5: 1-14. [CrossRef]

Peters, Micah, Christina Godfrey, Hana Khalil, Patricia McInerney, Deborah Parker, and Cassia Soares. 2015. Guidance for conducting systematic scoping reviews. International Journal of Evidence-Based Healthcare 13: 141-46. [CrossRef]

Plummer, Beverly. 2020. Civil Rights Has Always Been a Global Movement. Foreign Affairs, June 19. Available online: https: //www.foreignaffairs.com/articles/united-states/2020-06-19/civil-rights-has-always-been-global-movement (accessed on 20 October 2021).

Quiocho, Alice, and Francisco Rios. 2000. The power of their presence: Minority group teachers and schooling. Review of Educational Research 70: 485-528. [CrossRef]

Ramos, Blanca, James Jaccard, and Vincent Guilamo-Ramos. 2003. Dual ethnicity and depressive symptoms: Implications of being Black and Latino in the United States. Hispanic Journal of Behavioral Sciences 25: 147-73. [CrossRef]

Reece, Robert. 2019a. Coloring racial fluidity: How skin tone shapes multiracial adolescents' racial identity changes. Race and Social Problems 11: 290-98. [CrossRef]

Reece, Robert. 2019b. Coloring Weight Stigma: On Race, Colorism, Weight Stigma, and the Failure of Additive Intersectionality. Sociology of Race and Ethnicity 5: 388-400. [CrossRef]

Reece, Robert. 2019c. Color Crit: Critical Race Theory and the History and Future of Colorism in the United States. Journal of Black Studies 50: 3-25. [CrossRef] 
Reece, Robert. 2021. The Future of American Blackness: On Colorism and Racial Reorganization. The Review of Black Political Economy 48: 481-505. [CrossRef]

Rondilla, Joanne, and Paul Spickard. 2007. Is Lighter Better?: Skin-Tone Discrimination among Asian Americans. Lanham: Rowman \& Littlefield.

Russell, Kathy, Midge Wilson, and Ronald Hall. 1993. The Color Complex: The Politics of Skin Color among African Americans. New York: Anchor Books.

Ryabov, Igor. 2013. Colorism and school-to-work and school-to-college transitions of African American adolescents. Race and Social Problems 5: 15-27. [CrossRef]

Ryabov, Igor. 2016. Educational outcomes of Asian and Hispanic Americans: The significance of skin color. Research in Social Stratification and Mobility 44: 1-9. [CrossRef]

Ryabov, Igor. 2019. How much does physical attractiveness matter for Blacks? linking skin color, physical attractiveness, and Black status attainment. Race and Social Problems 11: 68-79. [CrossRef]

Ryabov, Igor, and Franklin Goza. 2014. Phenotyping and adolescence-to-adulthood transitions among Latinos. Race and Social Problems 6: 342-55. [CrossRef]

Santana, Emilce. 2018. Situating perceived discrimination: How do skin color and acculturation shape perceptions of discrimination among Latinos? The Sociological Quarterly 59: 655-77. [CrossRef]

Shelton, J. Nicole, Tiffany Yip, Jacquelynne Eccles, Celina Chatman, Andrew Fuligni, and Carol Wong. 2005. Ethnic identity as a buffer in psychological adjustment. In Navigating the Future: Social Identity, Coping, and Life Tasks. Edited by Downey Geraldine Eccles and Celina Chatman. New York: Russell Sage Foundation, pp. 96-114.

Stephens, Dionne, Paula Fernández, and Erin Richman. 2012. Ni pardo, ni prieto: The influence of parental skin color messaging on heterosexual emerging adult White-Hispanic women's dating beliefs. Women E Therapy 35: 4-18. [CrossRef]

Telzer, Eva, and Heidie Vazquez Garcia. 2009. Skin color and self-perceptions of immigrant and US-born Latinas: The moderating role of racial socialization and ethnic identity. Hispanic Journal of Behavioral Sciences 31: 357-74. [CrossRef]

Thompson, Maxine, and Steve McDonald. 2015. Race, skin tone, and educational achievement. Sociological Perspectives 59: 91-111. [CrossRef]

Tricco, Andrea, Erin Lillie, Wasifa Zarin, Kelly O'Brien, Heather Colquhoun, Danielle Levac, David Moher, Micah Peters, Tanya Horsley, Laura Weeks, and et al. 2018. PRISMA extension for scoping reviews (PRISMA-ScR): Checklist and explanation. Annals of Internal Medicine 169: 467. [CrossRef] [PubMed]

Uhlmann, Eric Dasgupta, Angelica Elgueta, Anthony Greenwald, and Jane Swanson. 2002. Subgroup prejudice based on skin color among Hispanics in the United States and Latin America. Social Cognition 20: 198-225. [CrossRef]

Vasquez, Jessica. 2010. Blurred borders for some but not "Others": Racialization, "flexible ethnicity," gender, and third-generation Mexican American identity. Sociological Perspectives 53: 45-71. [CrossRef] 